\title{
Total versus near-total thyroidectomy in Graves' disease: a systematic review and meta-analysis of comparative studies
}

\author{
Lan $\mathrm{Mu}^{1} \wedge$, Chutong Ren ${ }^{1}$, Jiangyue $\mathrm{Xu}^{1}$, Can Guo ${ }^{1}$, Jiangsheng Huang ${ }^{1}, \mathrm{Ke} \mathrm{Ding}^{2}$ \\ ${ }^{1}$ Department of Thyroid Surgery, the Second Xiangya Hospital, Central South University, Changsha, China; ${ }^{2}$ Department of Urology, Xiangya \\ Hospital, Central South University, Changsha, China \\ Contributions: (I) Conception and design: L Mu, C Ren; (II) Administrative support: J Huang; (III) Provision of study materials or patients: C Ren; (IV) \\ Collection and assembly of data: L Mu, J Xu, K Ding; (V) Data analysis and interpretation: L Mu, J Xu, C Guo; (VI) Manuscript writing: All authors; \\ (VII) Final approval of manuscript: All authors. \\ Correspondence to: Jiangsheng Huang. Department of Thyroid Surgery, The Second Xiangya Hospital, Central South University, No. 139 Remin \\ Middle Road, Changsha 410000, China. Email: hjs13907313501@csu.edu.cn; Ke Ding. Department of Urology, Xiangya Hospital, Central South \\ University, Changsha 410000, China. Email: dingke@csu.edu.cn.
}

Background Total thyroidectomy (TT), near-total thyroidectomy (NT), and subtotal thyroidectomy (ST) are three surgical procedures for Graves' disease (GD) patients, but most previous studies have only evaluated the complications of TT versus ST or TT/NT versus ST; there is not a meta-analysis of NT versus TT, so whether NT is superior to TT for GD patients still unclear.

Methods: We comprehensively searched PubMed, Embase, Web of Science, and the Cochrane Library, without restriction to region, publication type, or language, on 10 June, 2020. We conducted this systematic review and meta-analysis of all included studies assessing the two surgical procedures.

Results: In total, 528 cases were identified from two randomized controlled trials (RCTs) and three retrospective studies. The incidence of permanent hypoparathyroidism after NT was lower than with TT [odds ratio (OR), 0.22; 95\% confidence interval (CI), 0.06-0.80; $\mathrm{P}=0.02$ ], and there was no statistical difference in the recurrence of hyperthyroidism (OR, 0.33; 95\% CI, 0.01-8.12; $\mathrm{P}=0.50)$ and other postoperative complications $(\mathrm{P}>0.05)$.

Conclusions: NT for GD was superior to TT regarding permanent hypoparathyroidism, but there was no significant difference in preventing recurrent hyperthyroidism, as well as the other postoperative complications.

Keywords! Graves' disease (GD); near-total thyroidectomy (NT); total thyroidectomy (TT)

Submitted Oct 13, 2020. Accepted for publication Dec 31, 2020.

doi: $10.21037 /$ gs-20-757

View this article at: http://dx.doi.org/10.21037/gs-20-757

\section{Introduction}

Graves' disease (GD), a common autoimmune disease (1), is mainly caused by autoantibodies' production against thyroid-stimulating hormone (TSH) receptors, which stimulates the follicular cells to overproduce. About $0.5-2 \%$ of the population is affected by GD, which is the root cause of $50-80 \%$ of hyperthyroidism cases (2-4). GD's clinical manifestations include diffuse goiter, ophthalmopathy or orbital disease, skin disease (anterior tibial or localized mucin edema), tachycardia and so on. About $50 \%$ of GD patients develop Grave's ophthalmopathy (GO), and 5\% of GD patients have severe GO (5).

The goals of treatment for GD patients are to quickly

^ ORCID: 0000-0003-1571-042X. 
resolve the hyperthyroidism and its related symptoms, prevent and treat sequelae, diagnose and treat occasional thyroid carcinoma, delay the progression of GO and skin lesions, and prevent recurrence (6). For GD patients, there are three main treatments: antithyroid drugs (ATDs), radioactive iodine (RAI), and thyroidectomy. These treatments have their strengths and utilization. Different indications, geographic regions, and patient/ clinician preferences influence selection. RAI is the first choice in the USA, whereas, in Europe and Asia, it is ATDs or thyroidectomy (7). Patients receiving ATDs have the highest recurrence rate $(\approx 40 \%)$, RAI $(21 \%)$ ranks second, and patients have the lowest recurrence rate after thyroidectomy $(<5 \%)(8,9)$. Generally speaking, drug therapy is the first choice of initial treatment, and if it fails or the disease recurs, RAI ablation or thyroidectomy is the second option. Moreover, in some cases, thyroidectomy is considered the best therapeutic option for GD, such as suspected malignant nodules, severe GO, large goiters with oppression symptoms, failure of RAI, or pregnant woman hyperthyroidism $(5,10)$.

There are three surgical procedures for GD: total thyroidectomy (TT), whose purpose is to achieve a complete macroscopic resection of thyroid tissue; near-total thyroidectomy (NT) with remnant $\leq 1 \mathrm{~g}$ thyroid remnant on each side; and subtotal thyroidectomy (ST), which includes two surgical methods: bilateral subtotal thyroidectomy (BST) refers to bilateral thyroid residual of $2-4 \mathrm{~g}$, and unilateral total and contralateral ST (Dunhill procedure) with a thyroid residual $<7 \mathrm{~g}(11,12)$.

There is no doubt that the curative effect of thyroidectomy for GD is definite, but the optimal extent of resection is not yet clear. Regarding the two commonly used surgical procedures, TT and ST, many previous studies have compared their advantages and disadvantages. A meta-analysis of five randomized controlled trials (RCTs) in 2015 found that in preventing the recurrence of hyperthyroidism, TT was more effective than BST and Dunhill procedure, but TT increased the risk of permanent hypoparathyroidism when compared with ST (13). A review in 2019 concluded that a high-volume thyroid surgeon who performed TT was the preferred surgical therapy for GD (6), but this conclusion was only based on many research results of TT versus ST and did not involve NT. Additionally, NT and TT were sometimes used interchangeably in previous studies (14). Based on the scope of resection of NT being larger than that of ST, but without complete removal of the thyroid, we wondered if the incidence of hypoparathyroidism and the risk of recurrence of hyperthyroidism would be lower after NT due to preservation of the parathyroid glands, and thus be a superior surgical choice to TT. So far, there has not been a meta-analysis of NT versus TT, so we collected existing original studies related to TT and NT and performed a meta-analysis to quantify the two surgical procedures' potential advantages. We present the following article in accordance with the PRISMA reporting checklist (available at http://dx.doi.org/10.21037/gs-20-757).

\section{Methods}

\section{Registration}

We successfully registered this systematic review on PROSPERO (registration no. CRD42020201770).

\section{Search strategy}

The literature search was performed on June 10, 2020, regardless of geographic region, publication type or language. The databases we searched were PubMed, Embase, Web of Science, and the Cochrane Library. The $\mathrm{MeSH}$ terms and their combinations were searched in [Title/Abstract] as follows: "total thyroidectomy" and "near total thyroidectomy" and "Graves' disease/toxic goiter". We also used the related articles function to broaden the search. When multiple reports involving the same crowd were published, we used the latest and complete study.

\section{Inclusion and exclusion criteria}

Two investigators screened all abstracts and titles independently and determined eligible studies based on the following criteria.

Inclusion criteria: (I) prospective, retrospective, randomized or controlled clinical trials; (II) clinical studies comparing patients treated by NT or TT; (III) patients with GD.

Exclusion criteria: (I) studies not designed as prospective, retrospective, randomized, controlled trials; (II) editorials, letters, reviews, case reports or experimental animal studies; (III) poor reporting of related outcome indicators.

\section{Data extraction and outcomes of interest}

The original data of the included studies were independently extracted and summarized by two researchers (L Mu and C 


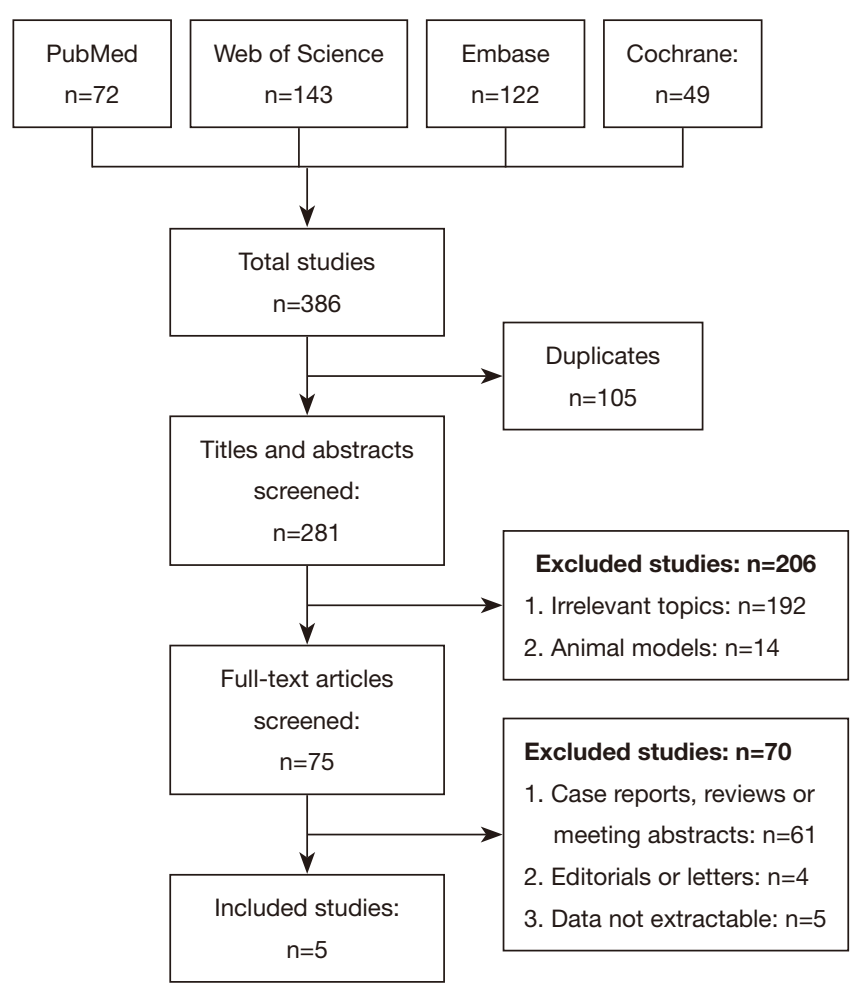

Figure 1 Flowchart of the study selection procedure.

Ren). Any disagreement was resolved by a third researcher (J $\mathrm{Xu})$. The two researchers used a standardized form for data extraction, which included characteristics of the original studies (authors, year of publication, area, study type, etc.) and the outcomes of each trial [primary outcomesrecurrent hyperthyroidism, transient hypoparathyroidism; and secondary outcomes-permanent hypoparathyroidism, transient recurrent laryngeal nerve palsy (RLNP), permanent RLNP, ophthalmopathy progression, and postoperative bleeding].

\section{Quality assessment and statistical analysis}

Among the included trials, the RCTs were assessed by the Cochrane bias risk assessment tool (15) for methodological quality. The retrospective studies were assessed by the Newcastle-Ottawa scale (NOS) (16), which included three factors: patient selection (4 items), comparability (2 items), and exposure (3 items).

Each study was assigned a score of $0-9$, and those with a score $\geq 6$ were considered high quality. Review Manager 5.4 was utilized to analyze the extracted data. Odds ratio $(\mathrm{OR})$ and $95 \%$ confidence interval (CI) were calculated for each trial. The chi-square $\left(\chi^{2}\right)$ test and $\mathrm{I}^{2}$ test were used to evaluate heterogeneity. If $\mathrm{P}<0.05$ or $\mathrm{I}^{2}>50 \%$, the heterogeneity was considered significant. The randomeffects model was used if $\mathrm{I}^{2}>50 \%$; otherwise, the fixedeffect model was used. Sensitivity analysis was performed by excluding individual studies stepwise to analyze the study's effect on the overall results. Unfortunately, we did not perform subgroup analysis and evaluate publication bias because of the limited number of trials.

\section{Results}

\section{Literature search}

A total of 386 records were retrieved through the literature search. After preliminary screening, we screened out 75 fulltext papers for the next step of screening, while 311 studies were excluded because they did not meet the inclusion criteria or were irrelevant topics. Finally, there were five studies (17-21) that met the predetermined inclusion criteria, with 528 cases $(207$ cases of NT and 321 cases of TT) for meta-analysis. The flowchart of the selection process is shown in Figure 1.

\section{Characteristics of the included studies}

The characteristics of the included studies are shown in Table 1. These trials were published between 1999 and 2019, 2 of which were from Germany, and the other 3 were from Australia, the USA, and Japan, respectively. Two RCTs $(18,21)$ with the level of evidence of $1 \mathrm{a}$ and $1 \mathrm{~b}$, and, and 3 retrospective studies $(17,19,20)$ with the level of evidence of 4 , $2 \mathrm{~b}$ and $2 \mathrm{~b}$. In terms of surgical indications, comprehensively, they mainly included recent hyperthyroidism/early relapse, oppression symptoms, failed drug therapy, and patient preference. As for the surgery scope, in the vast majority of patients with remnant thyroid after NT, it was $<1 \mathrm{~mL}$; in the only study (20) it was $<2 \mathrm{~mL}$. Follow-up ranged from 1 to 14 years but was mostly $1-5$ years

\section{Methodological quality of the included studies}

The quality of the included studies was not high (Table 2, Figure $2 A, B)$. The two RCTs did not describe the random allocation method and allocation concealment. In one study, the patients and observers were blinded, the results data were complete, and reporting bias and other biases were not found (21), but these parameters were not described in 
Table 1 Characteristics of included studies

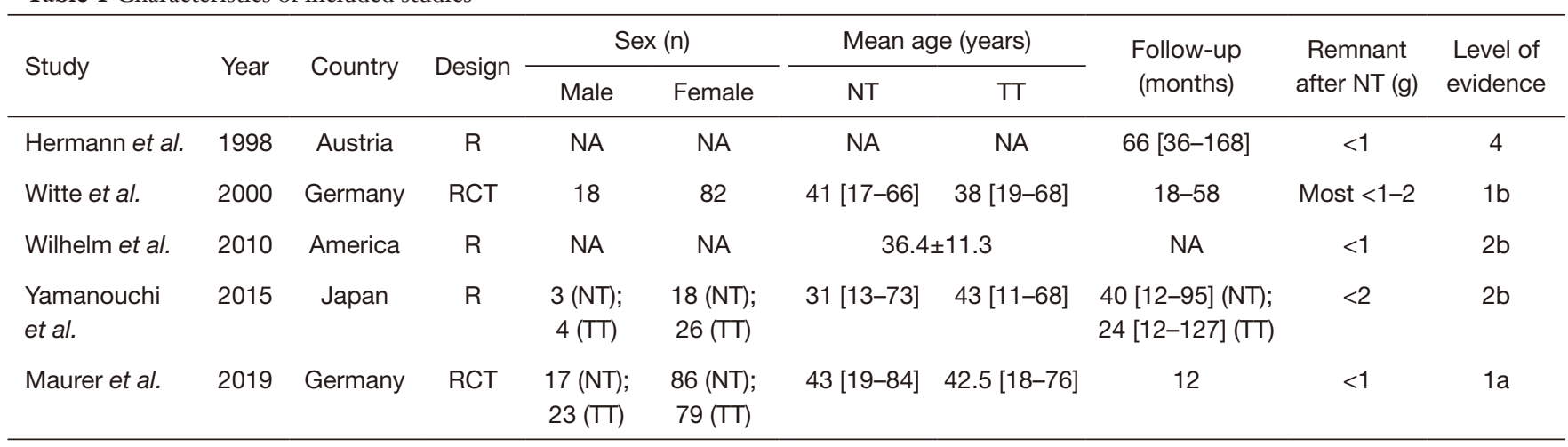

NA, data not available; NT, near-total thyroidectomy; R, retrospective; RCT, randomized controlled trial; TT, total thyroidectomy.

Table 2 Methodological quality of three retrospective studies

\begin{tabular}{|c|c|c|c|c|c|c|c|c|c|c|}
\hline \multirow[b]{2}{*}{ Study } & \multicolumn{4}{|c|}{ Selection [4] } & \multirow{2}{*}{\multicolumn{2}{|c|}{$\begin{array}{c}\text { Comparability } \\
{[2]} \\
\text { Comparability } \\
\text { based on } \\
\text { the design or } \\
\text { analysis }\end{array}$}} & \multicolumn{3}{|c|}{ Exposure [3] } & \multirow[b]{2}{*}{$\begin{array}{l}\text { Total } \\
\text { scores }\end{array}$} \\
\hline & $\begin{array}{l}\text { Representativeness } \\
\text { of the exposed }\end{array}$ & $\begin{array}{c}\text { Selection } \\
\text { of the } \\
\text { nonexposed }\end{array}$ & $\begin{array}{c}\text { Exposure } \\
\text { ascertainment }\end{array}$ & $\begin{array}{c}\text { The outcome } \\
\text { was not } \\
\text { present at } \\
\text { the start }\end{array}$ & & & $\begin{array}{l}\text { Assessment } \\
\text { of outcome }\end{array}$ & $\begin{array}{l}\text { Follow-up } \\
\text { long } \\
\text { enough }\end{array}$ & $\begin{array}{l}\text { Adequacy } \\
\text { of follow-up }\end{array}$ & \\
\hline $\begin{array}{l}\text { Hermann } \\
\text { et al. } 1998\end{array}$ & 1 & 0 & 1 & 1 & 0 & 0 & 1 & 1 & 0 & 5 \\
\hline $\begin{array}{l}\text { Wilhelm } \\
\text { et al. } 2010\end{array}$ & 1 & 0 & 1 & 1 & 0 & 0 & 1 & 1 & 0 & 5 \\
\hline $\begin{array}{l}\text { Yamanouchi } \\
\text { et al. } 2015\end{array}$ & 1 & 0 & 1 & 1 & 0 & 1 & 1 & 1 & 0 & 6 \\
\hline
\end{tabular}

the other RCT (18). As for the three retrospective studies $(17,19,20)$, none used an appropriate plan to allocate treatment, and the allocation was usually determined by the surgeon, there was also no description of the methods of dealing with missing data and intention-to-treat analysis. Four studies reported the duration of follow-up, and the perioperative data was provided in all studies.

\section{Primary outcomes}

\section{Recurrent hyperthyroidism}

Only one case of recurrence was observed in the TT group of one trial (21), and there was no recurrence reported in the other four trials. The analysis results showed no significant difference in recurrent hyperthyroidism between NT and TT groups (OR, 0.33; 95\% CI, 0.01-8.12; $\mathrm{P}=0.50$ ) (Figure 3).

\section{Transient hypoparathyroidism}

Four trials reported the incidence of transient hypoparathyroidism (18-21): there was no difference between the NT and TT groups in the incidence of postoperative transient hypoparathyroidism (OR, 0.55; 95\% CI, 0.16-1.90; $\mathrm{P}=0.34$ ) (Figure 4). The $\chi^{2}$ test showed an evident trend for heterogeneity among the trials (transient hypoparathyroidism, $\mathrm{P}=0.0007, \mathrm{I}^{2}=75 \%$ ) (Figure 4), so the random-effects model was used. To find the source of heterogeneity, we rechecked whether the original data included in the study was correct; after checking and verifying that nothing was wrong, we used the stepwise method of removing individual studies to eliminate each study, and we found that when this study (18) was eliminated, the effect statistic OR was replaced with risk ratio (RR), the $\mathrm{I}^{2}$ dropped from $75 \%$ to $47 \%$, indicating that this study may have been the primary source of 

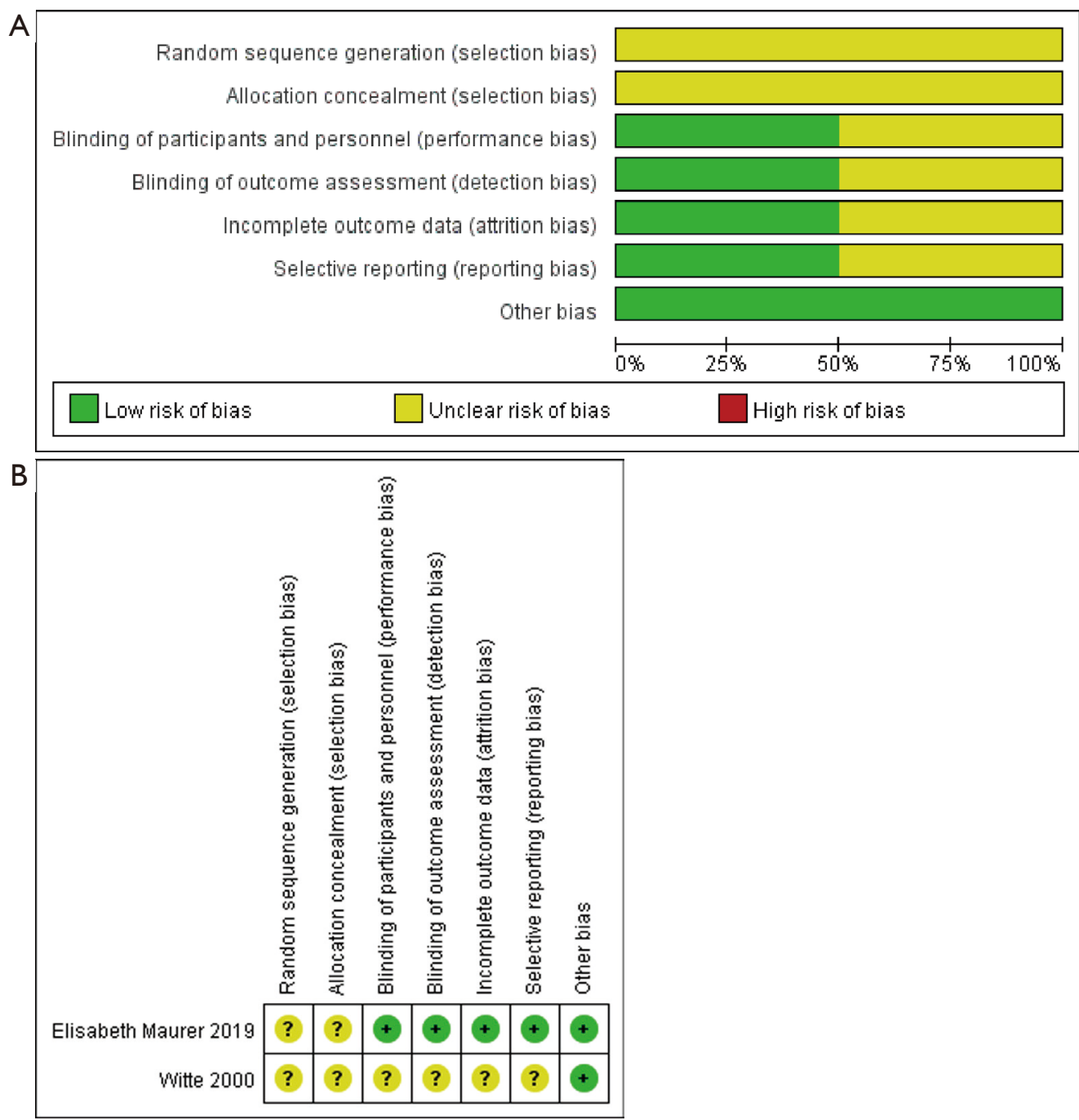

Figure 2 Risk of bias. (A) Judgments of review authors on the risk of each bias item presented as percentages; (B) summary of review authors' judgments on the risk of each bias item.

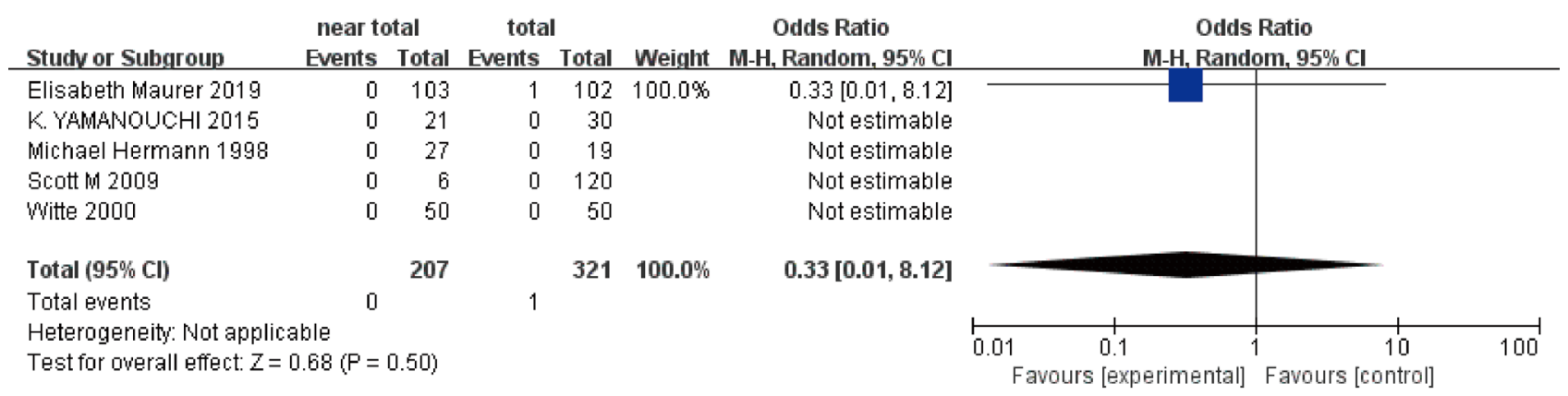

Figure 3 Forest plot of comparison of near-total thyroidectomy versus total thyroidectomy for the outcome of recurrent hyperthyroidism. CI, confidence interval. 


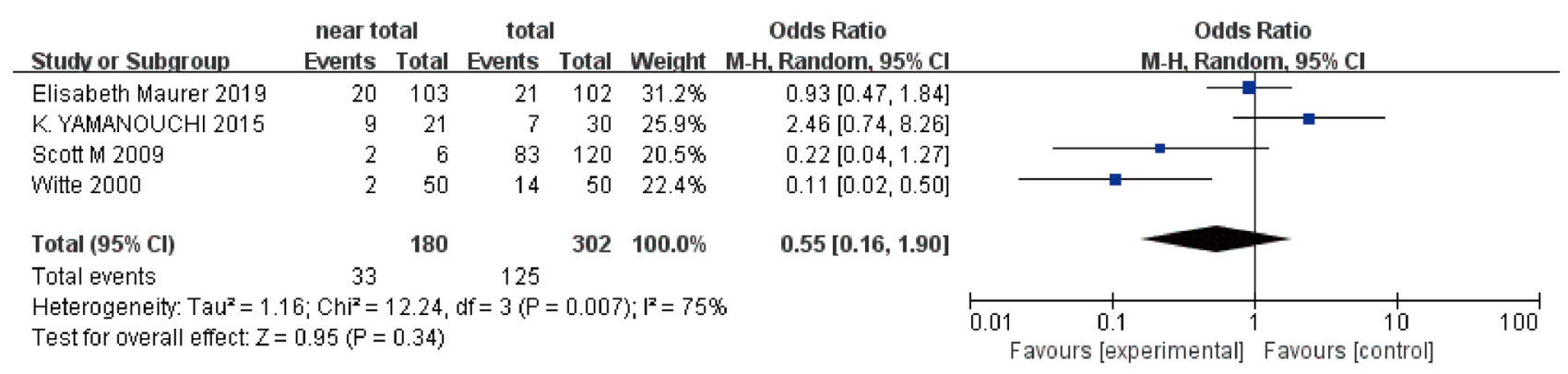

Figure 4 Forest plot of comparison of near-total thyroidectomy versus total thyroidectomy for the outcome of transient hypoparathyroidism. CI, confidence interval.

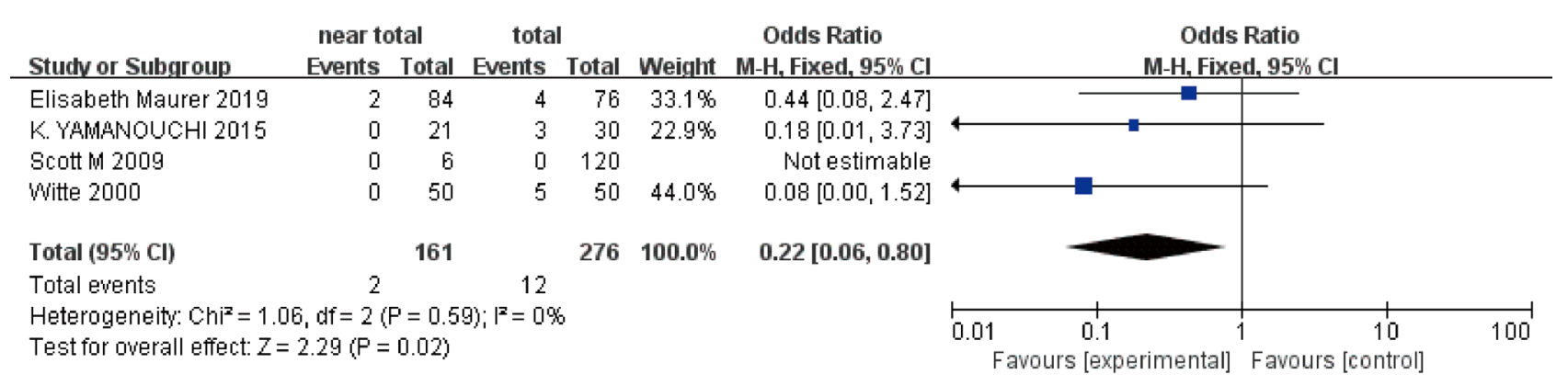

Figure 5 Forest plot of comparison of near-total thyroidectomy versus total thyroidectomy for the outcome of permanent hypoparathyroidism. CI, confidence interval.

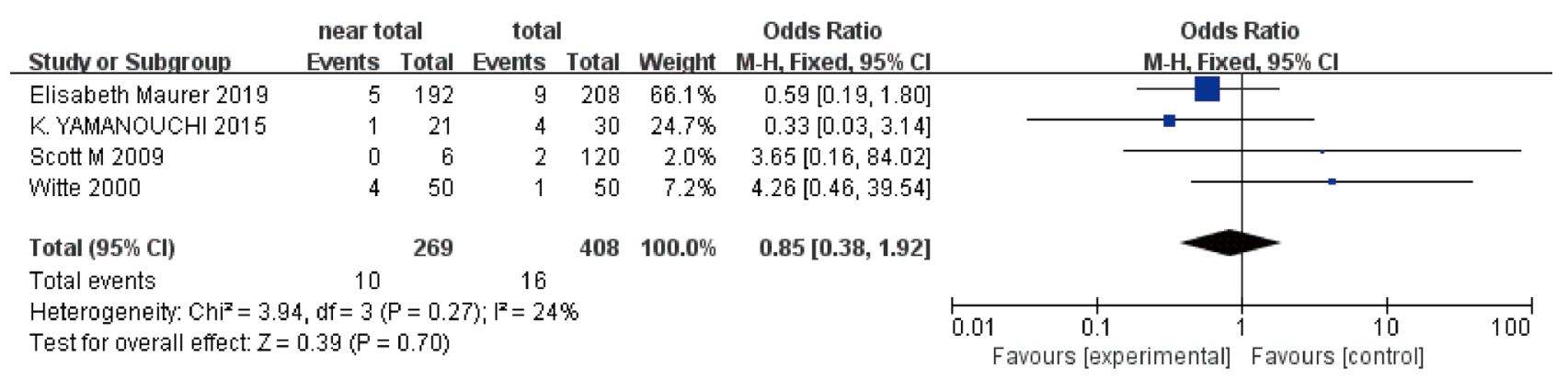

Figure 6 Forest plot of comparison of near-total thyroidectomy versus total thyroidectomy for the outcome of transient RLNP. CI, confidence interval; RLNP, recurrent laryngeal nerve palsy.

heterogeneity, but there were also no substantial differences in the results (RR, 1.01; 95\% CI, 0.54-1.91; $\mathrm{P}=0.97 ; \mathrm{I}^{2}=47 \%$ ) with the elimination of this study.

\section{Secondary outcomes}

\section{Permanent hypoparathyroidism}

More cases of permanent postoperative hypoparathyroidism were observed in the TT group (OR, 0.22; 95\% CI, 0.06$0.80 ; \mathrm{P}=0.02)$, and it indicated no heterogeneity among the trials (Chi-square $=1.06 ; \mathrm{P}=0.59 ; \mathrm{I}^{2}=0 \%$ ) (Figure 5).

\section{Transient RLNP}

No significant difference between NT and TT groups were observed when transient RLNP was analyzed (OR, 0.85; 95\% CI, 0.38-1.92; P=0.70; $\mathrm{I}^{2}=24 \%$ ) (Figure 6). 


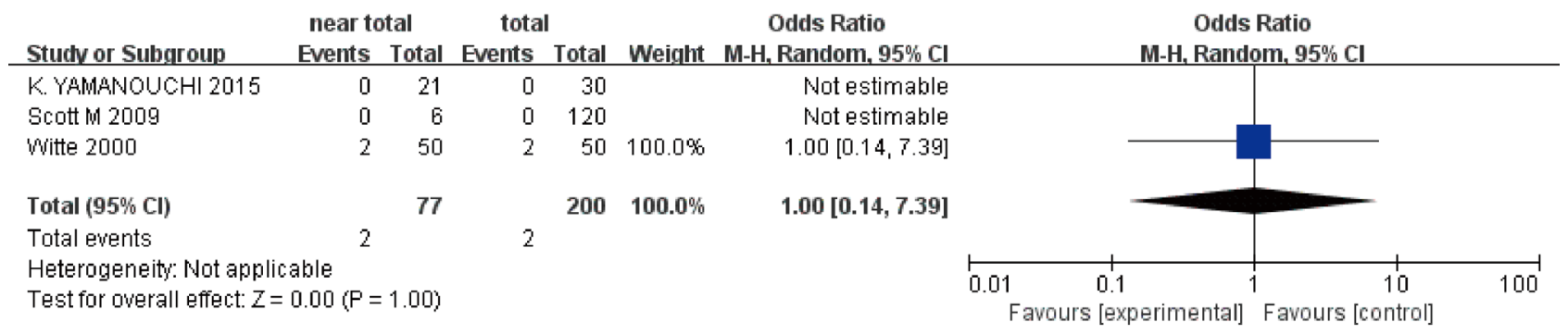

Figure 7 Forest plot of comparison of near-total thyroidectomy versus total thyroidectomy for the outcome of permanent RLNP. CI, confidence interval; RLNP, recurrent laryngeal nerve palsy.

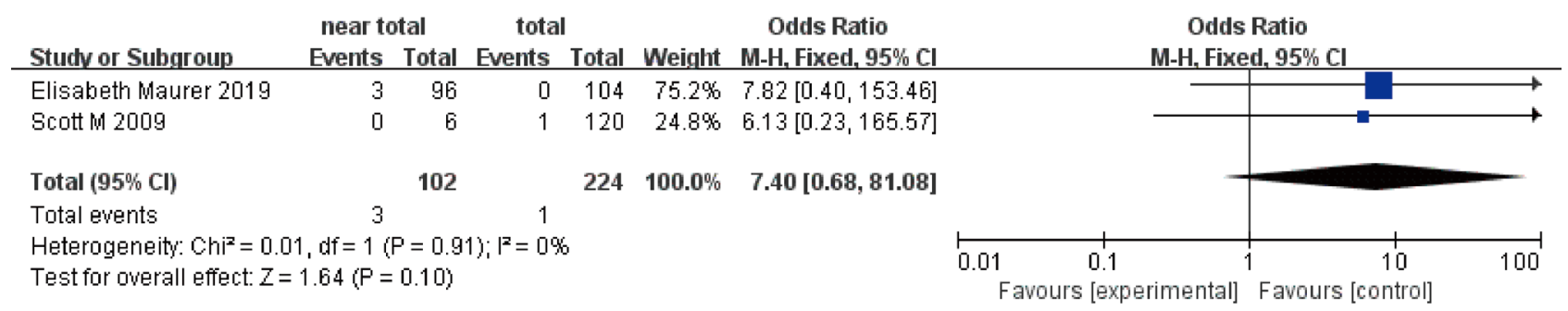

Figure 8 Forest plot of comparison of near-total thyroidectomy versus total thyroidectomy for the outcome of postoperative bleeding. CI, confidence interval.

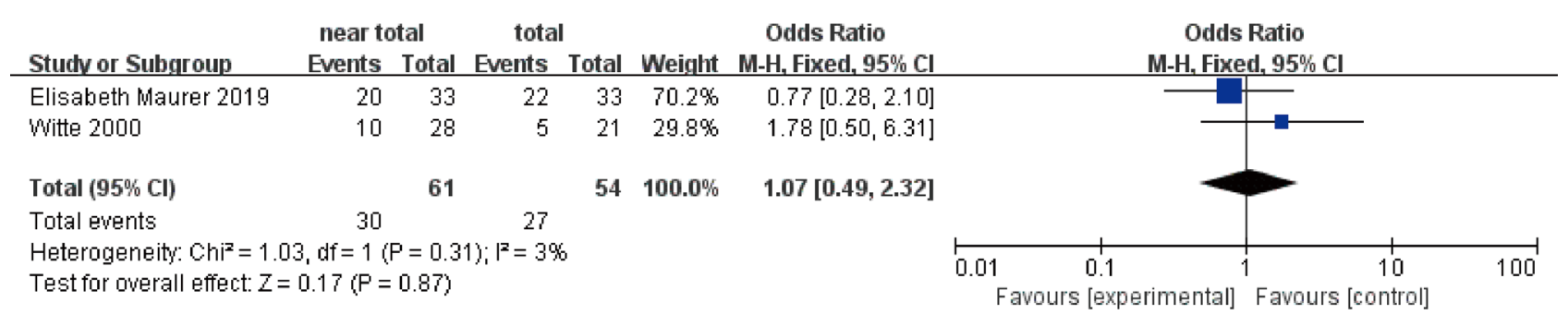

Figure 9 Forest plot of comparison of near-total thyroidectomy versus total thyroidectomy for the outcome of ophthalmopathy progression. CI, confidence interval.

\section{Permanent RLNP}

Three trials (18-20) reported the incidence of permanent RLNP, which indicated there was no significant difference in the incidence of postoperative permanent RLNP between the 2 groups (OR, $1.00 ; 95 \% \mathrm{CI}, 0.14-7.39 ; \mathrm{P}=1.00)$ (Figure 7).

\section{Postoperative bleeding}

Only two trials $(19,21)$ reported postoperative bleeding, and the risk of postoperative bleeding, and there was still no statistical difference among NT and TT groups (OR, 7.40;
95\% CI, 0.68-81.08; $\mathrm{P}=0.10 ; \mathrm{I}^{2}=0 \%$ ) (Figure 8 ).

\section{Ophthalmopathy progression}

Two trials $(18,21)$ reported progression of ophthalmopathy, and there was also no significant difference between NT and TT groups (OR, 1.07; 95\% CI, 0.49-2.32; $\mathrm{P}=0.87$; $\mathrm{I}^{2}=3 \%$ ) (Figure 9).

\section{Subgroup analyses}

Because of the limited number of original studies, which is 
not enough to assess different subgroups' effects, we did not conduct subgroup analysis.

\section{Sensitivity analyses}

When we examined each outcome event for sensitivity analysis by using different effect models, the results were similar between fixed-effect and random-effect models for the incidence of outcome events. Similarly, when we examined each outcome event using different effect size statistics (OR or RR), there were no substantial differences in the results.

\section{Assessment of reporting bias}

We did not construct funnel plots owing to our limited number of studies per outcome $(n=5)$.

\section{Discussion}

In the 1940s, thyroidectomy was introduced as a treatment for GD. Still, because of its higher risk of postoperative complications, it was replaced by RAI therapy as the first choice for GD (22). However, with the continuous development of modern surgical techniques, thyroidectomy has become a fast and permanent treatment option for GD patients to return to normal thyroid hormone levels $(23,24)$. The preferred surgical option for GD has changed in the past 20 years, from ST to TT $(10,25)$. Previous studies have shown that compared with ST, TT has a higher incidence of permanent complications $(26,27)$. However, more recent studies have shown that in a large-volume facility with experienced surgeons, the incidence of complications is similar between the two surgical procedures, and TT has the absolute advantage of preventing recurrent hyperthyroidism $(13,23,28)$.

To date, few studies have differentiated NT and TT. On the contrary, more often than not, these terms are often used interchangeably in some references. However, NT refers to leaving $<1 \mathrm{~g}$ of thyroid remnant bilaterally, whereas TT removes all visible thyroid tissue. It may be difficult for surgeons to distinguish the two surgical procedures in clinical practice if the thyroid remnant is not specifically identified and measured. For example, in a multicenter RCT, NT was described exactly, with remnant tissue of $0.5 \times 0.5 \times 0.5 \mathrm{~cm}^{3}$ in size at most $(\leq 1 \mathrm{~g})$, and the surgical site was photographed after resection for monitoring purposes (21). If NT can indeed benefit patients, even if the operation is much difficult, it is necessary to define which procedure is being performed clearly.

In this study, we compared the therapeutic effects of NT and TT in GD and the incidence of correlative complications. NT seemed to be more effective than $\mathrm{TT}$ in preventing permanent hypoparathyroidism. In terms of recurrence of hyperthyroidism, transient hypoparathyroidism, and transient or permanent RLNP, there was no significant difference between the two surgical procedures. Also, only two trials reported on ophthalmopathy progression and postoperative bleeding, and the results of the meta-analysis also showed no significant difference between NT and TT.

The results of our meta-analysis were slightly different from the results of the single trials. The latest RCT showed that NT was not superior to TT in terms of postoperative complications, but the risk of inadvertently removing the parathyroid glands and postoperative bleeding tended to be higher after NT, so they preferred TT in the surgical treatment of GD comparing with NT (21). However, another study indicated the rate of transient postoperative RLNP was significantly higher in the TT group $(\mathrm{P}<0.001)$, and they believed that NT for GD was a reasonable operative option regarding both efficacy and safety (20).

Transient or permanent hypoparathyroidism can lead to postoperative hypocalcemia $(29,30)$, and consequently, patients need to take calcium and vitamin D tablets daily. Previous large-scale registry studies have pointed out that postoperative hypoparathyroidism is the main complication after GD surgery $(31,32)$. Even transient postoperative hypoparathyroidism will affect the patients' health and quality of life (33). Therefore, in our research, it seemed that NT for GD was superior to TT regarding postoperative permanent hypoparathyroidism. We think that the high incidence of permanent hypoparathyroidism after TT may be because the operation is more likely to damage the parathyroid glands when compared with NT, NT retains less than $1 \mathrm{gm}$ of thyroid tissue on each side, as it mentioned in the study by Maurer et al. (21), their remnant was left at the superior suspensory ligament of Berry, where is a dangerous area because of high risk of damage to the recurrent laryngeal nerve and parathyroid glands during surgery, so the parathyroid glands' damage will be slightly less, the corresponding incidence of hypoparathyroidism is also lower. Besides, the incidence of postoperative hypoparathyroidism may be lower because the risk of intraoperative devascularization of the upper parathyroid glands is reduced. However, this conclusion 
comes from a meta-analysis based on limited raw data, and the corresponding accuracy and credibility were limited. We intend to search for more high-quality studies on NT and $\mathrm{TT}$ in the future to provide stronger evidence for guiding the surgical treatment of GD patients.

\section{Study limitations}

Because of the limited number of original trials as the subject of this research, not all were RCTs, and the quality of the included trials was not high. Also, some outcome indicators were reported in only two trials, which was far from enough for a good meta-analysis.

\section{Conclusions}

This study is the first meta-analysis comparing NT with TT in the treatment of GD. We found that NT was superior to TT concerning permanent hypoparathyroidism, but there was no significant difference in preventing recurrent hyperthyroidism, as well as the other postoperative complications.

\section{Acknowledgments}

We acknowledge the authors who provided the original studies, and thank the professors and colleagues who helped and supported us in this research.

Funding: This work was supported by the National Key R\&D Program of China under Grant 2019YFE0190500.

\section{Footnote}

Reporting Checklist: The authors have completed the PRISMA reporting checklist. Available at http://dx.doi. org/10.21037gs-20-757

Peer Review File: Available at http://dx.doi.org/10.21037/gs20-757

Conflicts of Interest: All authors have completed the ICMJE uniform disclosure form (available at http://dx.doi. org/10.21037/gs-20-757). The authors have no conflicts of interest to declare.

Ethical Statement: The authors are accountable for all aspects of the work in ensuring that questions related to the accuracy or integrity of any part of the work are appropriately investigated and resolved.

Open Access Statement: This is an Open Access article distributed in accordance with the Creative Commons Attribution-NonCommercial-NoDerivs 4.0 International License (CC BY-NC-ND 4.0), which permits the noncommercial replication and distribution of the article with the strict proviso that no changes or edits are made and the original work is properly cited (including links to both the formal publication through the relevant DOI and the license). See: https://creativecommons.org/licenses/by-nc-nd/4.0/.

\section{References}

1. Liu J, Bargren A, Schaefer S, et al. Total thyroidectomy: a safe and effective treatment for Graves' disease. J Surg Res 2011;168:1-4.

2. Brent GA. Clinical practice. Graves' disease. N Engl J Med 2008;358:2594-605.

3. Woeber KA. Triiodothyronine production in Graves' hyperthyroidism. Thyroid 2006;16:687-90.

4. Toft AD. Clinical practice. Subclinical hyperthyroidism. N Engl J Med 2001;345:512-6.

5. Bahn Chair RS, Burch HB, Cooper DS, et al. Hyperthyroidism and other causes of thyrotoxicosis: management guidelines of the American Thyroid Association and American Association of Clinical Endocrinologists. Thyroid 2011;21:593-646.

6. Bobanga ID, McHenry CR. Treatment of patients with Graves' disease and the appropriate extent of thyroidectomy. Best Pract Res Clin Endocrinol Metab 2019;33:101319.

7. Wartofsky L, Glinoer D, Solomon B, et al. Differences and similarities in the treatment of diffuse goiter in Europe and the United States. Exp Clin Endocrinol 1991;97:243-51.

8. Akram S, Elfenbein DM, Chen H, et al. Assessing American Thyroid Association Guidelines for Total Thyroidectomy in Graves' Disease. J Surg Res 2020;245:64-71.

9. Schneider DF, Sonderman PE, Jones MF, et al. Failure of radioactive iodine in the treatment of hyperthyroidism. Ann Surg Oncol 2014;21:4174-80.

10. Ross DS, Burch HB, Cooper DS, et al. 2016 American Thyroid Association Guidelines for Diagnosis and Management of Hyperthyroidism and Other Causes of Thyrotoxicosis. Thyroid 2016;26:1343-421.

11. Dunhill TP. A Discussion on Partial Thyroidectomy under 
Local Anæsthesia, with Special Reference to Exophthalmic Goitre: An Address Introductory to a Discussion on the Subject. Proc R Soc Med 1912;5:61-9.

12. Müller PE, Bein B, Robens E, et al. Thyroid surgery according to Enderlen-Hotz or Dunhill: a comparison of two surgical methods for the treatment of Graves' disease. Int Surg 2001;86:112-6.

13. Liu ZW, Masterson L, Fish B, et al. Thyroid surgery for Graves' disease and Graves' ophthalmopathy. Cochrane Database Syst Rev 2015;(11):CD010576.

14. Cirocchi R, Trastulli S, Randolph J, et al. Total or neartotal thyroidectomy versus subtotal thyroidectomy for multinodular non-toxic goitre in adults. Cochrane Database Syst Rev 2015;(8):CD010370.

15. Cumpston M, Li T, Page MJ, et al. Updated guidance for trusted systematic reviews: a new edition of the Cochrane Handbook for Systematic Reviews of Interventions. Cochrane Database Syst Rev 2019;10:ED000142.

16. Stang A. Critical evaluation of the Newcastle-Ottawa scale for the assessment of the quality of nonrandomized studies in meta-analyses. Eur J Epidemiol 2010;25:603-5.

17. Hermann M, Roka R, Richter B, et al. Early relapse after operation for Graves' disease: postoperative hormone kinetics and outcome after subtotal, near-total, and total thyroidectomy. Surgery 1998;124:894-900.

18. Witte J, Goretzki PE, Dotzenrath C, et al. Surgery for Graves' disease: total versus subtotal thyroidectomyresults of a prospective randomized trial. World J Surg 2000;24:1303-11.

19. Wilhelm SM, McHenry CR. Total thyroidectomy is superior to subtotal thyroidectomy for management of Graves' disease in the United States. World J Surg 2010;34:1261-4.

20. Yamanouchi K, Minami S, Kuba S, et al. Evaluation of the operative methods for Graves' disease. Minerva Chir 2015;70:77-81.

21. Maurer E, Maschuw K, Reuss A, et al. Total Versus Neartotal Thyroidectomy in Graves Disease: Results of the Randomized Controlled Multicenter TONIG-trial. Ann Surg 2019;270:755-61.

22. Jin J, Sandoval V, Lawless ME, et al. Disparity in the management of Graves' disease observed at an urban county hospital: a decade-long experience. Am J Surg 2012;204:199-202.

23. Palit TK, Miller CC, Miltenburg DM. The efficacy of thyroidectomy for Graves' disease: A meta-analysis. J Surg Res 2000;90:161-5.
24. Werga-Kjellman P, Zedenius J, Tallstedt L, et al. Surgical treatment of hyperthyroidism: a ten-year experience. Thyroid 2001;11:187-92.

25. Barakate MS, Agarwal G, Reeve TS, et al. Total thyroidectomy is now the preferred option for the surgical management of Graves' disease. ANZ J Surg 2002;72:321-4.

26. Barczyński M, Konturek A, Hubalewska-Dydejczyk A, et al. Randomized clinical trial of bilateral subtotal thyroidectomy versus total thyroidectomy for Graves' disease with a 5-year follow-up. Br J Surg 2012;99:515-22.

27. Järhult J, Rudberg C, Larsson E, et al. Graves' disease with moderate-severe endocrine ophthalmopathy-long term results of a prospective, randomized study of total or subtotal thyroid resection. Thyroid 2005;15:1157-64.

28. Guo Z, Yu P, Liu Z, et al. Total thyroidectomy vs bilateral subtotal thyroidectomy in patients with Graves' diseases: a meta-analysis of randomized clinical trials. Clin Endocrinol (Oxf) 2013;79:739-46.

29. Erbil Y, Ozbey NC, Sari S, et al. Determinants of postoperative hypocalcemia in vitamin D-deficient Graves' patients after total thyroidectomy. Am J Surg 2011;201:685-91.

30. Promberger R, Ott J, Kober F, et al. Normal parathyroid hormone levels do not exclude permanent hypoparathyroidism after thyroidectomy. Thyroid 2011;21:145-50.

31. Hallgrimsson P, Nordenström E, Almquist M, et al. Risk factors for medically treated hypocalcemia after surgery for Graves' disease: a Swedish multicenter study of 1,157 patients. World J Surg 2012;36:1933-42.

32. Bartsch DK, Dotzenrath C, Vorländer C, et al. Current Practice of Surgery for Benign Goitre-An Analysis of the Prospective DGAV StuDoQ IThyroid Registry. J Clin Med 2019;8:477.

33. Arlt W, Fremerey C, Callies F, et al. Well-being, mood and calcium homeostasis in patients with hypoparathyroidism receiving standard treatment with calcium and vitamin D. Eur J Endocrinol 2002;146:215-22.

(English Language Editors: K. Brown and J. Chapnick)

Cite this article as: $\mathrm{Mu} \mathrm{L}$, Ren C, Xu J, Guo C, Huang J, Ding $\mathrm{K}$. Total versus near-total thyroidectomy in Graves' disease: a systematic review and meta-analysis of comparative studies. Gland Surg 2021;10(2):729-738. doi: 10.21037/gs-20-757 